\title{
TINGKAT KEPUASAAN WISATAWAN MANCANEGARA TERHADAP KUALITAS PELAYANAN REKREASI AIR PT PANDAWA MARINE ADVENTURS DI TANJUNG BENOA
}

\author{
Ida Bagus Udayana Pidada \\ Program Studi Magister Kajian Pariwisata \\ Universitas Udayana \\ Email: udayanapidada@gmail.com
}

\begin{abstract}
PT Pandawa Marine Adventures is a company that is operated in the sector of marine tourism as a place for water recreation which is very popular among the travellers for playing water sport activities in the area of Tanjung Benoa. This study aims to analyse customer satisfaction related to the service quality of PT Pandawa Marine Adventures. The research used 100 respondents selected as the samples by using accidental sampling method. The collected data were then analyzed by descriptive qualitative method.The result of this study show that the tourists satisfaction related to the quality service of PT Pandawa Marine Adventures were measured into five satisfaction dimensions (tangible, reliability, responsiveness, assurance, empathy) by using 20 variables. The tangible dimension with four variables obtaining average value as amount 4,18 with satisfied category. Reliability with three variables obtaining average value as amount 4,06 with satisfied category. Responsiveness has six variables obtaining average value as amount 4,09 with satisfied category. Assurance has four variables and obtaining average value 4,07 with satisfied category. Empathy has three variables and obtaining average value 4,27 with very satisfied category.
\end{abstract}

Keywords: satisfaction, foreign tourist, service quality 


\section{Pendahuluan}

Selama ini orientasi pembangunan pariwisata Indonesia lebih Serfokus kepada land based development, belum pada sea based development. Orientasi pengembangan wisata berbasis lautan cukup beralasan mengingat luas wilayah Indonesia 74,4\% adalah laut dengan panjang garis pantai $99.096 \mathrm{~km}$ (Badan Informasi Geospasial 2013) merupakan salah satu yang terpanjang di dunia. Sumber daya laut Indonesia terbilang sangat besar, merupakan modal besar dan terbuka luas untuk pengembangan usaha-usaha rekreasi industri kepariwisataan di Indonesia termasuk di dalamnya adalah perairan sepanjang pantai, danau, dan sungai di Bali.

Rekreasi air di Tanjung Benoa banyak mendapat kunjungan wisatawan karena menawarkan jasa pelayanan baik berupa sarana atau produk rekeasi air. Rekreasi Air PT Pandawa Marine Adventures adalah salah satu dari 24 rekreasi air yang berada di Tanjung Benoa dan merupakan rekreasi air yang sampai saat ini paling favorit di Kawasan Tanjung Benoa. Rekreasi air PT Pandawa Marine Adventures digemari kalangan wisatawan karena pihak pengelola menerapkan konsep wisata air Tropical Island Garden, yaitu menyiapkan dan menawarkan fasilitas rekreasi air yang modern dan lengkap dengan nuansa yang sejuk dan menyenangkan. Konsep Tropical Island Garden dari pihak pengelola ternyata mampu menyedot dan menambah minat wisatawan untuk datang ke tempat Rekreasi Air PT Pandawa Marine Adventures.

Penelitian ini dilakukan pada oleh peneliti berangkat dari keingintahuan peneliti tentang pendapat wisatawan, khususnya mancanegara terhadap kualitas pelayanan di perusahaan ini. Oleh sebab itu, peneliti menganalisis tingkat kepuasan wisatawan mancanegara terhadap kualitas pelayanan tempat rekreasi air PT Pandawa Marine Adventures dilihat dari segi lima dimensi kepuasan (Tangibel, Reliability, Responsiveness, Assurance, Emphaty). Hal ini penting dilakukan agar dapat menilai apakah pelayanan selama ini dapat memenuhi dan memuaskan harapan wisatawan. Hasil temuan dianalisa dengan tujuan akhir memberikan saran 
dalam mengambil kebijakan selanjutnya. Kesemuanya hal ini bermanfaat untuk kelanjutan usaha tempat rekreasi PT Pandawa Marine Adventures agar dapat bertahan dan berkelanjutan di masa yang akan datang.

\section{Teori dan Metode}

Dalam pengelolaan usaha jasa pariwisata (hospitality) meliputi: (1) mengelola pelanggan baik secara pisik maupun psikologis, (2) pengelolaannya dapat diamati oleh pelanggan, (3) cara bagaimana tugas-tugas dikerjakan dan dikelola untuk menciptakan kepuasan pelanggan yang meliputi unsur-unsur yang kasat mata (tangible) maupun yang tidak kasat mata (intangible), (Suradnya 2006). Suatu produk tidak hanya terdiri dari produk yang nyata (tangible product), tetapi juga memiliki bentuk yang tidak nyata dalam bentuk pelayanan (intangible product). Teare (1994) menyebutkan pelayanan sebagai berikut: Pelayanan yang ditawarkan terdiri dari komponen yang berwujud dan tidak berwujud yang dirancang dan dikelola oleh produsen dengan tujuan memuaskan kebutuhan konsumen. Kualitas merupakan suatu yang harus dikerjakan dengan baik oleh pihak penyedia jasa.Aplikasi kualitas sebagai sifat-sifat dan penampilan produk atau kinerja merupakan bagian utama strategi perusahaan untuk meraih keunggulan yang berkesinambungan, baik sebagai pemimpin pasar maupun sebagai strategi untuk terus tumbuh.Keunggulan suatu produk jasa tergantung pada keunikan kualitas yang diperlihatkan, yaitu sesuai tidaknya dengan harapan atau keinginan konsumen. Salah satu cara agar penjualan jasa suatu perusahaan lebih unggul dibandingkan dengan para pesaingnya adalah dengan memberikan pelayanan yang berkualitas yang mampu memenuhi tingkat kepentingan konsumen. Tingkat kepentingan konsumen terhadap jasa yang akan mereka terima dapat dibentuk berdasarkan pengalaman dan saran yang mereka peroleh.

Penelitian ini menggunakan metode deskriptif kualitatif yaitu, mentransformasikan data mentah kedalam bentuk data yang mudah dipahami.Teknik pengumpulan data dilakukan dengan 
observasi, memberikan angket, wawancara mendalam, dan studi dokumentasi. Pengambilan sampel dalam penelitian ini dilakukan terhadap wisatawan mancanegara di lokasi tempat Rekreasi Air PT Pandawa Marine Adventures. Pengambilan sampel dilakukan secara kebetulan (accidental sampling) artinya pengambilan sampel dilakukan tanpa perencanaan yang seksama, dimana wisatawan mancanegara yang dimintai informasinya benar-benar diperoleh secara kebetulan tanpa suatu pertimbangan tertentu.

Menurut Malhotra (2006), untuk memperoleh hasil yang baik dalam suatu analisis faktor, banyaknya responden yang diambil untuk mengisi kuesioner sebanyak lima kali dari variabel yang dimuat dalam kuesioner. Dalam penelitian ini, jumlah variabel yang diteliti sebanyak 20, maka jumlah sampel yang diambil adalah sebanyak 5 × $20=100$ responden. Penelitian ini dilakukan selama tiga hari pada bulan Februari 2016.

Dalam menjawab permasalahan tentang tingkat kepuasan wisatawan mancanegara terhadap kualitas pelayanan pada tempat Rekreasi Air PT Pandawa Marine Adventure, perlu adanya definisi variable.Variable-variabel yang digunakan dalam penelitian ini adalah kepuasan wisatawan terhadap pelayanan. Selanjutnya atribut pelayanan tersebut dapat dilihat pada table 1.

Tabel 1. Dimensi dan Variabel / Indikator Kepuasan Wisatawan mancanegara Terhadap Pelayanan Tempat Rekreasi Air PT Pandawa Marine Adventure

\begin{tabular}{|c|c|c|c|}
\hline Konstruk & $\begin{array}{l}\text { Dimensi } \\
\text { Pelayanan }\end{array}$ & Variabel & Kode \\
\hline $\begin{array}{c}\text { Tingkat } \\
\text { Kepuasan } \\
\text { Wisatawan } \\
\text { Mancaneg- } \\
\text { ara }\end{array}$ & $\begin{array}{l}\text { Reliability } \\
\text { Respon- } \\
\text { siveness }\end{array}$ & 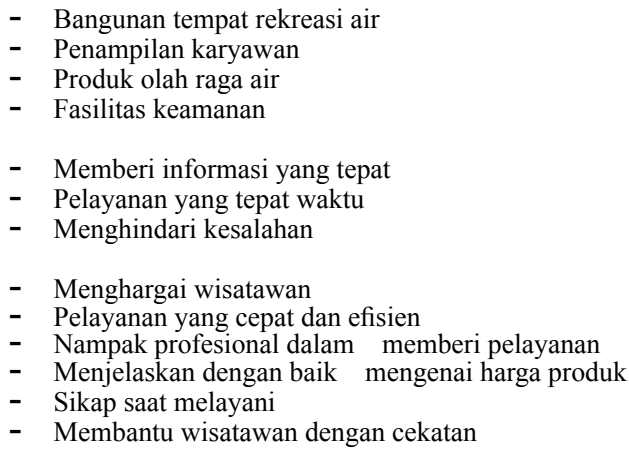 & $\begin{array}{l}\text { X1 } \\
\text { X2 } \\
\text { X3 } \\
\text { X4 } \\
\text { X5 } \\
\text { X6 } \\
\text { X7 } \\
\text { X8 } \\
\text { X9 } \\
\text { X10 } \\
\text { X11 } \\
X 12 \\
\text { X13 }\end{array}$ \\
\hline
\end{tabular}




\begin{tabular}{|l|l|l|l|}
\hline \multirow{3}{*}{ Assurance } & - Pengetahuan karyawan luas & \\
& - Bahasa mudah dan jelas & X14 \\
& - Jujur dan bersih & X16 \\
& - Xeamanan saat dilayani \\
& Emphaty & - Memanggil nama wisatawan & \\
& - Memberi perhatian terhadap permintaan wisatawan & X19 \\
& - Murah senyum & X20 \\
\hline
\end{tabular}

Sumber: Modifikasi Parasuraman (dalam Tjiptono dkk. 2004)

Penelitian ini menggunakan metode statistik deskriptif, yaitu dimana dalam teknik analisis ini tingkat kepuasan wisatawan dianalisis dengan bantuan skala Likert. Dalam penelitian ini, data dari jawaban responden yang didapatkan diolah dengan menggunakan program SPSS. Dalam penelitian ini aspek pertanyaan kuisioner yang mencakup lima dimensi kualitas pelayanan akan diberikan pembobotan nilai yang terdiri dari sangat puas (SP) dengan skor 5, puas (P) dengan skor 4, cukup puas (CP) dengan skor 3, kurang puas (KP) dengan skor 2, dan tidak puas (TP) dengan skor 1 .

Nilai rata-rata skor dari sampel responden tidak selamanya memiliki nilai bulat, kemungkinan akan diperoleh nilai pecahan. Oleh karena itu, perlu dibuat nilai interval kelas yang disesuaikan dengan jumlah kelas yang diinginkan, yang mana dalam skala Likert adalah terdiri dari lima kelas. Sedangkan nilai interval kelas, dapat dihitung sebagai berikut:

$$
C i=\frac{\text { Kisaran (range) }}{K} \quad \mathrm{Ci}=\frac{5-1}{5}=\underline{4}=0,8
$$

\section{Keterangan:}

Range $=$ Selisih nilai tertinggi dan terendah $=5-1=4$

$\mathrm{Ci}=$ Interval kelas $>$ dihitung

$\mathrm{K}=$ Jumlah kelas yang diinginkan $>5$ kelas 
Tabel 2. Kategori Kepuasan Wisatawan Mancanegara Terhadap Kualitas Pelayanan Tempat Rekreasi Air PT Pandawa Marine Adventures, Tanjung Benoa

\begin{tabular}{|l|l|l|}
\hline Skor & \multicolumn{1}{|c|}{ Kategori } & \multicolumn{1}{|c|}{$\begin{array}{c}\text { Kisaran Skor } \\
\text { (Nilai Riil) }\end{array}$} \\
\hline 1 & Sangat Tidak Puas & $1,0-<1,8$ \\
2 & Kurang Puas & $1,8-<2,6$ \\
3 & Cukup Puas & $2,6-<3,4$ \\
4 & Puas & $3,4-<4,2$ \\
5 & Sangat Puas & $4,2-<5$ \\
\hline
\end{tabular}

(Sumber :Data Kelas Interval)

\section{Pembahasan}

Analisis kepuasan wisatawan terhadap kualitas pelayanan Rekreasi Air PT Pandawa Marine Adventures, dimaksudkan untuk melihat tingkat kepuasan wisatawan terhadap masingmasing variabel kualitas pelayanan Rekreasi Air PT Pandawa Marine Adventure Tanjung Benoa.

Berdasarkan nilai rata-rata penilaian responden untuk masing-masing variabel dari kelima dimensi, kemudian dimasukkan ke dalam kategori tingkat kepuasan wisatawan, maka di dapat hasil variabel kualitas pelayanan adalah sebagai berikut:

\section{Dimensi Tangible}

Berdasarkan hasil tabulasi data jawaban responden terhadap empat variabel tentang tangible yang dijawab oleh 100 orang responden, persentasenya disajikan pada Tabel 3 sebagai berikut: 
Tingkat Kepuasaan Wisatawan Mancanegara Terhadap Kualitas Pelayanan Rekreasi Air Pan...

Tabel 3. Tingkat Kepuasan Responden Terhadap Dimensi Tangible

\begin{tabular}{|c|c|c|c|c|c|c|c|c|c|c|}
\hline \multirow{2}{*}{ No } & \multirow{2}{*}{$\begin{array}{c}\text { Variabel } \\
\text { Tentang } \\
\text { Tangible }\end{array}$} & \multicolumn{5}{|c|}{ Jawaban Responden } & \multirow{2}{*}{$\begin{array}{c}\text { Jumlah } \\
\text { Respon- } \\
\text { den }\end{array}$} & \multirow{2}{*}{$\begin{array}{l}\text { Jum- } \\
\text { lah } \\
\text { Skor }\end{array}$} & \multirow{2}{*}{$\begin{array}{l}\text { Rata- } \\
\text { Rata }\end{array}$} & \multirow{2}{*}{ Ket } \\
\hline & & 1 & 2 & 3 & 4 & 5 & & & & \\
\hline 1 & $\begin{array}{l}\text { X1. Bangunan } \\
\text { tempat } \\
\text { rekreasi air }\end{array}$ & 0 & 0 & 0 & 72 & 28 & 100 & 428 & 4,28 & $\begin{array}{l}\text { San- } \\
\text { gat } \\
\text { Puas }\end{array}$ \\
\hline 2 & $\begin{array}{l}\text { X2. } \\
\text { Penampiln } \\
\text { karyawan }\end{array}$ & 0 & 0 & 6 & 71 & 23 & 100 & 417 & 4,17 & Puas \\
\hline 3 & $\begin{array}{l}\text { X3. Produk } \\
\text { olah raga air }\end{array}$ & 0 & 0 & 5 & 76 & 19 & 100 & 414 & 4,14 & Puas \\
\hline 4 & $\begin{array}{l}\text { X4. Fasilitas } \\
\text { keamanan }\end{array}$ & 0 & 0 & 3 & 83 & 14 & 100 & 411 & 4,11 & Puas \\
\hline & Rata-rata & & & & & & & & 4,18 & Puas \\
\hline
\end{tabular}

Sumber: Data olahan

Terlihat bahwa tiga variabel berada pada kategori puas yaitu: variabel penampilan karyawan (X2) dengan nilai rata-rata 4,17; variabel wahana olah raga air (X3) dengan nilai rata-rata 4,14; variabel fasilitas keamanan (X4) dengan nilai rata-rata 4,11; sedangkan variabel bangunan tempat rekreasi air (X1) berada kategori sangat puas dengan nilai rata-rata 4,28. Jika melihat nilai rata-rata skor dari empat variabel mengenai tangible yaitu sebesar 4,18 yang berada pada kisaran 3,4 - 4,2 yang berarti dalam kategori puas.

\section{Dimensi Reliability}

Berdasarkan hasil tabulasi data, jawaban responden terhadap tiga variabel tentang reliability yang dijawab oleh 100 orang responden, yang persentasenya disajikan pada Tabel 4 sebagai berikut: 
Tabel 4. Tingkat Kepuasan Responden Terhadap

Dimensi Reliability

\begin{tabular}{|c|c|c|c|c|c|c|c|c|c|c|}
\hline \multirow{2}{*}{ No } & \multirow{2}{*}{$\begin{array}{c}\text { Variabel } \\
\text { Tentang } \\
\text { Reliabiilty }\end{array}$} & \multicolumn{5}{|c|}{ Jawaban Responden } & \multirow{2}{*}{$\begin{array}{c}\text { Jumlah } \\
\text { Respon- } \\
\text { den }\end{array}$} & \multirow{2}{*}{$\begin{array}{l}\text { Jum- } \\
\text { lah } \\
\text { Skor }\end{array}$} & \multirow{2}{*}{$\begin{array}{l}\text { Rata- } \\
\text { Rata }\end{array}$} & \multirow{2}{*}{ Ket } \\
\hline & & 1 & 2 & 3 & 4 & 5 & & & & \\
\hline 1 & $\begin{array}{l}\text { X5.Memberi } \\
\text { informasi yang } \\
\text { tepat }\end{array}$ & 0 & 0 & 2 & 87 & 11 & 100 & 409 & 4,09 & Puas \\
\hline 2 & $\begin{array}{l}\text { X6.Pelayanan } \\
\text { yang tepat } \\
\text { waktu }\end{array}$ & 0 & 1 & 4 & 84 & 11 & 100 & 405 & 4,05 & Puas \\
\hline 3 & $\begin{array}{l}\text { X7. Menghin- } \\
\text { dari kesalahan }\end{array}$ & 0 & 0 & 10 & 77 & 13 & 100 & 403 & 4,03 & Puas \\
\hline & Rata-rata & & & & & & & & 4,06 & Puas \\
\hline
\end{tabular}

Sumber: Data olahan

Berdasarkan Tabel 4, terlihat bahwa keseluruhan dari tiga variabel pada kategori puas yaitu: variabel memberi informasi yang tepat (X5) dengan nilai rata-rata 4,09; variabel pelayanan yang tepat waktu (X6) dengan nilai rata-rata 4,05; variabel menghindari kesalahan (X7) dengan nilai rata-rata 4,03. Jika melihat nilai ratarata skor dari tiga variabel mengenai reliability yaitu sebesar 4,06 yang berada pada kisaran 3,4-4,2 yang berarti pada kategori puas.

\section{Dimensi Responsiveness}

Tabel 5. Tingkat Kepuasan Responden Terhadap Dimensi Responsiveness

\begin{tabular}{|c|c|c|c|c|c|c|c|c|c|c|}
\hline \multirow{2}{*}{ No } & \multirow{2}{*}{$\begin{array}{l}\text { Variabel Ten- } \\
\text { tang Respon- } \\
\text { siveness }\end{array}$} & \multicolumn{5}{|c|}{ Jawaban Responden } & \multirow{2}{*}{$\begin{array}{l}\text { Jumlah } \\
\text { Re- } \\
\text { spon- } \\
\text { den } \\
\end{array}$} & \multirow{2}{*}{$\begin{array}{l}\text { Jum- } \\
\text { lah } \\
\text { Skor }\end{array}$} & \multirow{2}{*}{$\begin{array}{l}\text { Rata- } \\
\text { Rata }\end{array}$} & \multirow{2}{*}{ Ket } \\
\hline & & 1 & 2 & 3 & 4 & 5 & & & & \\
\hline 1 & $\begin{array}{l}\text { X8.Menghargai } \\
\text { wisatawan }\end{array}$ & 0 & 0 & 4 & 77 & 19 & 100 & 415 & 4,15 & Puas \\
\hline 2 & $\begin{array}{l}\text { X9. Pelayanan } \\
\text { yang cepat } \\
\text { dan efisien }\end{array}$ & 0 & 0 & 5 & 82 & 13 & 100 & 408 & 4,08 & Puas \\
\hline 3 & $\begin{array}{l}\text { X10.Nampak } \\
\text { profesional } \\
\text { dalam mem- } \\
\text { beri pelayanan }\end{array}$ & 0 & 0 & 6 & 84 & 10 & 100 & 404 & 4,04 & Puas \\
\hline
\end{tabular}

$84 \quad$ JUMPA Volume 05, Nomor 01, Juli 2018 
Tingkat Kepuasaan Wisatawan Mancanegara Terhadap Kualitas Pelayanan Rekreasi Air Pan...

\begin{tabular}{|l|l|l|l|l|l|l|l|l|l|l|}
\hline 4 & $\begin{array}{l}\text { X11.Menjelas- } \\
\text { kan dengan } \\
\text { baik men- } \\
\text { genai harga } \\
\text { produk }\end{array}$ & 0 & 2 & 4 & 78 & 16 & 100 & 408 & 4,08 & Puas \\
\hline 5 & $\begin{array}{l}\text { X12. Sikap saat } \\
\text { melayani }\end{array}$ & 0 & 0 & 5 & 83 & 12 & 100 & 407 & 4,07 & Puas \\
\hline 6 & $\begin{array}{l}\text { X13.Mem- } \\
\text { bantu wisa- } \\
\text { tawan dengan } \\
\text { cekatan }\end{array}$ & 0 & 0 & 6 & 79 & 15 & 100 & 409 & 4,09 & Puas \\
\hline & Rata-rata & & & & & & & 4,09 & Puas \\
\hline
\end{tabular}

Sumber: Data olahan

Berdasarkan Tabel 5, terlihat bahwa keseluruhan dari enam variabel dalam kategori puas yaitu: variabel menghargai wisatawan (X8) dengan nilai rata-rata 4,15; variabel pelayanan yang cepat dan efisien (X9) dengan nilai rata-rata 4,08; variabel nampak profesional dalam memberi pelayanan (X10) dengan nilai rata-rata 4,04; variabel menjelaskan dengan baik mengenai harga produk (X11) dengan nilai rata-rata 4,08; variabel sikap saat melayani (X12) dengan nilai rata-rata 4,07; variabel membantu wisatawan dengan cekatan (X13) dengan nilai rata-rata 4,09. Jika melihat nilai rata-rata skor dari enam variable mengenai responsiveness yaitu sebesar 4,09 yang berada pada kisaran 3,44,2 yang berarti pada kategori puas.

\section{Dimensi Assurance}

Tabel 6.Tingkat Kepuasan Responden Terhadap Dimensi Assurance

\begin{tabular}{|c|c|c|c|c|c|c|c|c|c|c|}
\hline \multirow[t]{2}{*}{ No } & \multirow{2}{*}{$\begin{array}{l}\text { Variabel Ten- } \\
\text { tang } \\
\text { Assurance }\end{array}$} & \multicolumn{5}{|c|}{ Jawaban Responden } & \multirow{2}{*}{$\begin{array}{l}\text { Jumlah } \\
\text { Re- } \\
\text { spon- } \\
\text { den }\end{array}$} & \multirow{2}{*}{$\begin{array}{l}\text { Jum- } \\
\text { lah } \\
\text { Skor }\end{array}$} & \multirow{2}{*}{$\begin{array}{l}\text { Rata- } \\
\text { Rata }\end{array}$} & \multirow[t]{2}{*}{ Ket } \\
\hline & & 1 & 2 & 3 & 4 & 5 & & & & \\
\hline 1 & $\begin{array}{l}\text { X14. Penge- } \\
\text { tahuan kary- } \\
\text { awan luas }\end{array}$ & 0 & 0 & 5 & 84 & 11 & 100 & 406 & 4,06 & Puas \\
\hline 2 & $\begin{array}{l}\text { X15. Bahasa } \\
\text { mudah dan } \\
\text { jelas }\end{array}$ & 0 & 1 & 5 & 85 & 9 & 100 & 402 & 4,02 & Puas \\
\hline
\end{tabular}




\begin{tabular}{|l|l|l|l|l|l|l|l|l|l|l|}
\hline 3 & $\begin{array}{l}\text { X16. Jujur dan } \\
\text { bersih }\end{array}$ & 0 & 0 & 14 & 71 & 15 & 100 & 401 & 4,01 & Puas \\
\hline 4 & $\begin{array}{l}\text { X17. } \\
\text { Keamanan } \\
\text { saat dilayani }\end{array}$ & 0 & 1 & 6 & 68 & 25 & 100 & 417 & 4,17 & Puas \\
\hline & Rata-rata & & & & & & & & 4,07 & Puas \\
\hline
\end{tabular}

Sumber: Data Olahan

Berdasarkan Tabel 6, terlihat bahwa keseluruhan dari empat variabel dalam kategori puas yaitu: pengetahuan karyawan (X14) dengan nilai 4,06; variabel bahasa mudah dan jelas (X15) dengan nilai rata-rata 4,02; variabel jujur dan bersih (X16) dengan nilai rata-rata 4,01; variabel keamanan saat melayani (X17) dengan nilai rata-rata 4,17. Jika melihat nilai rata-rata skor dari empat variabel mengenai assurance yaitu sebesar 4,07 yang berada pada kisaran 3,4 - 4,2 yang berarti pada kategori puas.

\section{Dimensi Emphaty}

Tabel 7. Tingkat Kepuasan Responden Terhadap Dimensi Emphaty

\begin{tabular}{|c|c|c|c|c|c|c|c|c|c|c|}
\hline \multirow[t]{2}{*}{ No } & \multirow{2}{*}{$\begin{array}{c}\text { Variabel Ten- } \\
\text { tang } \\
\text { Emphaty }\end{array}$} & \multicolumn{5}{|c|}{ Jawaban Responden } & \multirow{2}{*}{$\begin{array}{c}\text { Jumlah } \\
\text { Respon- } \\
\text { den }\end{array}$} & \multirow{2}{*}{$\begin{array}{l}\text { Jum- } \\
\text { lah } \\
\text { Skor }\end{array}$} & \multirow{2}{*}{$\begin{array}{l}\text { Rata- } \\
\text { Rata }\end{array}$} & \multirow[t]{2}{*}{ Ket } \\
\hline & & 1 & 2 & 3 & 4 & 5 & & & & \\
\hline 1 & $\begin{array}{l}\text { X18. Me- } \\
\text { manggil } \\
\text { nama wisa- } \\
\text { tawan }\end{array}$ & 0 & 0 & 7 & 74 & 19 & 100 & 412 & 4,12 & Puas \\
\hline 2 & $\begin{array}{l}\text { X19. } \\
\text { Memberi } \\
\text { perhatian } \\
\text { terhadap } \\
\text { permintaan } \\
\text { wisatawan }\end{array}$ & 0 & 0 & 0 & 72 & 28 & 100 & 428 & 4,28 & $\begin{array}{l}\text { Sangat } \\
\text { Puas }\end{array}$ \\
\hline 3 & $\begin{array}{l}\text { X20. Murah } \\
\text { senyum }\end{array}$ & 0 & 0 & 1 & 58 & 41 & 100 & 440 & 4,40 & $\begin{array}{l}\text { Sangat } \\
\text { Puas }\end{array}$ \\
\hline & Rata-rata & & & & & & & & 4,27 & $\begin{array}{l}\text { Sangat } \\
\text { Puas }\end{array}$ \\
\hline
\end{tabular}

Sumber: Data olahan 
Berdasarkan Tabel 7 terlihat bahwa dua variabel dalam kategori sangat puas yaitu: variabel memberi perhatian terhadap permintaan wisatawan (X19) dengan nilai rata-rata 4,28; variabel murah senyum (X20) dengan nilai rata-rata 4,40; sedangkan variabel memanggil nama wisatawan (X18) dengan nilai rata-rata 4,12 berada pada kategori puas. Jika melihat nilai rata-rata skor dari tiga variabel pernyataan mengenai emphaty yaitu sebesar 4,27 yang berada pada kisaran 4,2 - 5,0 yang berarti pada kategori sangat puas.

Secara umum rata-rata kepuasan wisatawan mancanegara terhadap kualitas pelayanan tempat Rekreasi Air PT Pandawa Marine Adventures pada level 4 dalam skala likert yaitu puas. Berdasarkan hasil analisis kepuasan wisatawan terhadap empat variabel dari tiga dimensi yang menyatakan kurang puas yaitu pada reliability dengan variabel: pelayanan yang tepat waktu (X6) dengan jumlah satu orang responden dari 100 responden wisatawan mancanegara. Responsiveness dengan variabel: menjelaskan dengan baik mengenai produk olah raga air (X11) dengan jumlah responden dua orang. Assurance dengan variabel: bahasa mudah dan jelas (X15)jumlah responden satu orang, keamanan saat dilayani (X17) jumlah responden satu orang. Dari hasil observasi di lapangan masih ditemukannya salah satu karyawan yang kurang memberikan pelayanan yang baik terhadap wisatawan. Seperti contoh di dalam memberikan pelayanan mengenai keamanan saat dilayani salah satu karyawan terlihat masih ada yang seolah-olah menganggap faktor keamanan adalah hal yang sepele saat menemani wisatawan menikmati wahana olah raga air, hal ini dikarenakan salah satu karyawan memang masih ada yang baru kerja di Rekreasi Air PT Pandawa Marine Adventures sehingga tidak memperhatikan SOP keamanan bagi wisatawan.

Terdapat 18 variabel dari lima dimensi yang menyatakan cukup puas yaitu tangible dengan variabel: penampilan karyawan (X2) dengan jumlah enam orang responden dari 100 orang responden wisatawan mancanegara, produk olah raga air (X3) 
dengan jumlah lima orang, fasilitas keamanan (X4) dengan jumlah tiga orang. Reliability dengan variabel: memberi informasi yang tepat (X5) dengan jumlah dua orang responden, pelayanan yang tepat waktu (X6) dengan jumlah empat orang, menghindari kesalahan (X7) dengan jumlah 10 orang. Responsiveness dengan variabel: menghargai wisatawan $(X 8)$ dengan jumlah empat orang, pelayanan yang cepat dan efisien (X9) dengan jumlah lima orang, nampak profesional dalam memberikan pelayanan (X10) dengan jumlah enam orang, menjelaskan dengan baik mengenai harga produk (X11) dengan jumlah empat orang, sikap saat melayani (X12) dengan jumlah lima orang, membantu wisatawan dengan cekatan (X13) dengan jumlah enam orang. Assurance dengan variabel: pengetahuan karyawan yang luas (X14) dengan jumlah lima orang, bahasa mudah dan jelas (X15) dengan jumlah lima orang, jujur dan bersih (X16) dengan jumlah 14 orang, keamanan saat dilayani (X17) dengan jumlah enam orang. Emphaty dengan variabel: memanggil nama wisatawan (X18) dengan jumlah tujuh orang, murah senyum (X20) dengan jumlah satu orang.

Hampir keseluruhan variabel berada pada level puas yaitu terdapat 19 variabel dan keseluruhan berada pada level sangat puas dengan 20 variabel. Hal ini sudah menunjukkan hal yang sangat positif dimana 20 variabel ini harus dipertahankan agar kepuasan wisatawan mancanegara terhadap kualitas pelayanan pada Rekreasi Air PT Pandawa Marine Adventures terjaga dengan baik. Berdasarkan pengamatan langsung di tempat ini, para staff handle sangat ramah saat melayani para wisatawan, ketika wisatawan baru tiba di Rekreasi Air PT Pandawa Marine Adventures, para staff langsung menyambut wisatawan dengan ramah dengan senyuman yang lebar, seraya memperkenalkan diri mereka dan menggiring wisatawan untuk duduk rehat sejenak sembari melihat pemandangan pantai yang indah disekitar tempat tersebut sebelum mereka dijelaskan tentang berbagai macam hal dan informasi. Pelayanan hal yang sekecil ini sudah sangat baik dirasakan oleh para wisatawan saat pertama menginjakkan kaki di tempat rekreasi air ini. Kegiatan usaha wisata bahari ini sudah 
dalam kategori sangat baik, akan tetapi perlu adanya dorongan dari pengelola kepada seluruh staff untuk lebih giat lagi dalam meningkatkan kualitas pelayanan terhadap wisatawan, supaya Rekreasi Air PT Pandawa Marine Adventures berada pada level sangat puas.

\section{Penutup}

Tingkat kepuasan wisatawan mancanegara terhadap kualitas pelayanan Rekreasi Air PT Pandawa Marine Adventures yaitu: pada dimensi tangible diperoleh nilai rata-rata 4,18 dengan kategori puas. Reliability diperoleh nilai rata-rata 4,06 dengan kategori puas. Responsiveness diperoleh nilai rata-rata 4,09 dengan kategori puas. Assurance diperoleh nilai rata-rata 4,07 dengan kategori puas. Emphaty diperoleh nilai rata-rata 4,27 dengan kategori sangat puas.

\section{Daftar Pustaka}

Badan Informasi Geospasial. 2013. "Panjang Garis Pantai Indonesia Mencapai 99.000 Kilometer" Available from: nationalgeographic. co.id. Diunduh tanggal 20 September 2015.

Likert, R. J. G. 1976. New Ways of Managing Conflicts. New York: Mc.

Graw Hill Book Company.

Malhotra, N. K. 2006. Riset Pemasaran Jilid 2, Edisi 4. Jakarta: PT Indeks.

Narka, M. 2011. Analisis Kualitatifdan Kuantitatif. Denpasar:Laboratorium, Fakultas Pertanian Unud.

Nasution, M. N. 2004. Manajemen Jasa Terpadu (Total Service Management). Jakarta: PT Ghalia Indonesia.

Paramesti, G. 2006. Panduan Lengkap SPSS 14.0 dalam Mengolah Data Statistik. Jakarta: PE Elex Media Komputindo.

Sugiarto, E. 2002. Psikologi Pelayanan Dalam Industri Jasa. Jakarta:

Gramedia Pustaka Utama.

Suwintari, E. 2010. “Kepuasan Wisatawan Terhadap Kualitas Pelayanan 
Tourist Information Counter di Jalan Padma Utara Legian Kuta" (tesis). Denpasar: Kajian Pariwisata, Pasca Sarjana Unud.

Supranto, J. 2004. Statistik Multivariat. Jakarta: Rineka Cipta.

Teare, R.. 1994. Marketing in Hospitality and Tourism A Consumer Focus. London: Cassell.

Tjiptono, F., Chandra, Y., Diana, A. 2004. Marketing scales. Penerbit Andi Yogyakarta, Yogyakarta.

\section{Profil Penulis}

Ida Bagus Udayana Pidada menyelesaikan Program Studi S-2 Kajian Pariwisata Universitas Udayana tahun 2016. Penulis menyelesaikan kuliah S-1 di Prodi Sastra Inggris Fakultas Ilmu Budaya (FIB) Universitas Udayana tahun 2012 dengan gelar Sarjana Sastra (S.S). Pada tahun 2014 Penulis bekerja sebagai Tour Guide Freelance dan juga bekerja sebagai karyawan pembantu untuk Gema Destinasi Wisata Tourand Travel (Gede Tour) di bawah payung Association of the Indonesian Tours and Travel Agencies (ASITA). 